\title{
Tinha um editor no meio do caminho, de José de Souza Muniz Jr.
}

\author{
Mário Vinícius Ribeiro Gonçalves' \\ 'Centro Federal de Educação Tecnológica de Minas Gerais, Belo Horizonte, MG, Brasil
}

Dando prosseguimento à publicação de Em busca do texto perfeito, de Ana Elisa Ribeiro (2016), e Quem mexeu no meu texto?, de Luciana Salazar Salgado (2017), o livro Tinha um editor no meio do caminho, do professor e pesquisador José de Souza Muniz Jr., lançado pelo selo Artigo A, da Gulliver Editora (Divinópolis-MG), vem para completar a trilogia que inaugura a série "Questões contemporâneas de edição, preparação e revisão textual". Trata-se de coleção bibliográfica cuja meta é acompanhar e abastecer de forma aprofundada, acessível e atual o debate e reflexão sobre as diversas práticas, atividades e processos editoriais. Esses aspectos, muitas vezes negligenciados em função do privilégio usualmente atribuído às noções de "obra" e "autoria", são aqui tratados enquanto protagonistas de uma trama que, embora seja geralmente encenada "nos bastidores", tem papel fundamental ao insuflar vida em textos e discursos, colocando-os em movimento sob as mais diversas atualizações - inclusive aquelas que, um tanto ironicamente, conservam a aparência coadjuvante dessas mesmas práticas, atividades e processos. Mas isso também não é por acaso, como Muniz Jr. procura demonstrar.

O livro é dividido em cinco capítulos, sendo o primeiro uma introdução. Os demais foram publicados, "em versões preliminares" (p. 130), em anais e atas de 
congressos nacionais e internacionais. O prefácio, de Luciana Salazar Salgado, é especialmente interessante ao chamar a atenção justamente para como o processo de dar unidade, na forma de livro, a artigos anteriormente publicados em outros contextos, faz com que esses textos não sejam mais os mesmos. Com efeito, a reconfiguração que cada retomada editorial ocasiona ao conjunto de nódulos intercomunicantes do ciclo de práticas sociais por meio das quais textos são escritos, lidos e publicados, é "pedra fundamental" (para nos servirmos do título do prefácio) na argumentação que Muniz Jr. tece no decorrer dos capítulos, sem que, no entanto, o autor caia na tentação de distorcer acriticamente os objetos de que se ocupa para poder encaixá-los em modelos teóricos preestabelecidos. Ao contrário: Muniz Jr., sem abrir mão de sólida fundamentação e do respeito pelo que estuda, não hesita em promover rupturas epistemológicas quando avalia que determinado referencial não dá conta de abarcar a complexidade e especificidade de cada caso.

Na introdução, "Sobras do publicar, dobras do dizer", Muniz Jr. situa a perspectiva adotada em suas reflexões. O autor traça um paralelo entre a noção de "ciência das sobras" - apelido que a antropologia havia recebido em seus princípios - e a atividade de editores, revisores e outros profissionais do texto, já que deles é frequentemente exigido um grande esforço para invisibilizar os traços de seu trabalho, a fim de, segundo essa lógica, realçar os elementos que realmente importariam no caminho da produção de sentido textual: a figura autoral e - mais recentemente - as diferentes formas de recepção dos objetos culturais. Sem desconsiderá-los, Muniz Jr. propõe uma terceira via possível: "o que é que existe, quem é que está e o que é que se faz no meio do caminho?" (p. 15). Para responder essas perguntas, o autor, de forma dialética, lança mão de uma "Análise de Discurso que pensa a produção editorial como trabalho, ou seja, como atividade humana situada no conflito entre o prescrito e o real" (p. 15-16) e da sociologia de Pierre Bourdieu, que, interessado em depurar as noções de "obra" e "autor" de qualquer misticismo a fim de compreender a dinâmica social a elas subjacente, propõe uma verdadeira "ciência das obras". Em sua síntese desses dois eixos teóricos, Muniz Jr. redireciona o foco da sociologia bourdieusiana da dimensão 
macro para o que se dá nas coxias do trabalho editorial. Segundo o autor, o convite que se pode depreender ao longo da leitura é o de, utilizando-se, como metáfora, do tsuru - origami que representa uma ave célebre no Japão -, partir das sobras para as dobras: "um desdobrar, eis o exercício proposto" (p. 19).

No capítulo seguinte, "Os desafios da palavra compartilhada", o autor inicia sua reflexão contrapondo a perspectiva linguístico-discursiva - que toma a enunciação, por natureza, como processo polifônico -, à prática efetiva de produção simbólica dentro da "indústria da língua" - que procura extrair do enunciado quaisquer marcas prévias de processualidade e multivocidade para, em seguida, estabelecer o texto: objeto autorizado a circular socialmente em sua pretensa univocidade. Ao analisar as múltiplas operações de retextualização, Muniz Jr. constata que, na realidade do mercado editorial, as nuances e fronteiras desses procedimentos nem sempre são bem definidas. O autor propõe, então, a via de mão dupla entre distanciamento críticoteórico e a consideração atenta ao cotidiano dos trabalhadores para que possam ser depreendidas, em toda sua historicidade, as relações entre as dimensões micro e macro da atividade editorial. O capítulo é então encaminhado para um estudo de caso em que, com base em conversas do autor com duas profissionais distintas envolvidas na produção de um livro didático - a autora e sua editora assistente -, conduzidas segundo um roteiro de autoconfrontação simples, é evidenciado o momento em que “a percepção de estilhaçamento da autoria a partir de fora (de um sujeito a quem a autoria não pertence) se converte na construção dessa mesma autoria, agora a quatro mãos" (p. 39). O binômio linguagem-trabalho, viés a partir do qual Muniz Jr. pretende assinalar sua contribuição ao debate das questões aqui levantadas, permanecerá fundamental para as reflexões dos capítulos subsequentes.

É justamente no terceiro capítulo, “O revisor na labuta: linguagem e/é trabalho” - criteriosamente posicionado no meio do caminho do livro -, que o binômio acima referido atingirá nova dimensão teórica, uma vez que é a partir desse ponto central que - de forma cruzada com a perspectiva linguística - a perspectiva ergológica será diretamente acionada, irradiando-se em direção às reflexões dos capítulos anteriores 
e posteriores, enriquecendo-as. Se para a ergologia a relação homem-natureza é mediada pelo trabalho, este ocupando efetivamente a lacuna que existe entre prescrição e realidade, é por intermédio da linguagem que os homens se relacionam entre si. Assim, os revisores de texto - uma vez que lidam tão explicitamente com a própria materialidade discursiva -, ao fazerem qualquer tipo de emenda, põem em movimento toda uma cena enunciativa em que são agenciadas uma pluralidade de vozes que precedem a intervenção e também aquelas que lhe são prospectivas. Dentro dessa perspectiva, é difícil não pensar no revisor como um coenunciador dentro de uma cenografia mais ampla: "textos não são fruto de um sujeito em cuja consciência muitas vozes se cruzam em polifonia. Temos um problema mais complexo: vários sujeitos incidem sobre o texto, a partir de seus respectivos repertórios, valores, condições." (p. 53). Desse ponto do capítulo em diante, Muniz Jr. serve-se do instrumental teórico apresentado para refletir sobre o que chama de "vozes da prescrição", isto é, manuais elaborados por editoras, jornais ou outras empresas, com o objetivo de orientar a atividade dos profissionais do texto em relação a padrões de revisão, redação, estilo etc. Embora tais publicações sejam frequentemente caracterizadas por um discurso em comum a favor de ideais de "clareza", "unidade" e "racionalidade", a realidade profissional muitas vezes exige que esses princípios sejam transgredidos em nome do "bom senso" - outro valor recorrentemente mencionado nesses documentos. Muniz Jr. ilustra esse argumento, já adentrando nas considerações finais do capítulo, por meio de um caso em que uma preparadora de originais, ao confrontar o arquivo que utilizara durante o trabalho em um livro, reconhece ter recorrido a uma estratégia de esquiva de uma norma para não ter de burlá-la, já que acatá-la, no momento de transição em questão - em que passava a vigorar o Novo Acordo Ortográfico -, poderia perturbar a percepção dos leitores.

O quarto capítulo, "Da edição-metáfora à edição-objeto", abre com considerações a respeito da diferenciação que se faz, em inglês, entre editor e publisher: aquele se ocupa do trabalho em si de produção editorial - frequentemente envolvendo a manipulação direta da materialidade textual -, ao passo que este lida com os diversos 
aspectos econômicos da publicação enquanto negócio. Em países de língua portuguesa essa distinção sistemática é inexistente, podendo o profissional denominado "editor" realizar tarefas de ambas as naturezas. Feitas essas observações, Muniz Jr. procede à análise de Art Worlds (1982), obra do sociólogo estadunidense Howard S. Becker. A noção de "mundos da arte" é definida por Becker (citado por Muniz Jr.) como "a rede de pessoas cuja atividade cooperativa, organizada através de seu conhecimento conjunto dos meios convencionais de fazer coisas, produz o tipo de trabalhos artísticos que caracterizam o mundo da arte" (p. 75). Para Becker todo trabalho artístico apresenta, em maior ou menor grau, indícios de sua natureza coletiva, que podem dizer respeito tanto à atuação direta de profissionais de apoio de determinado mundo da arte quanto a presunções e projeções que os artistas fazem do público e da crítica e que podem influir no próprio processo de criação. Tendo situado as linhas gerais das ideias de Becker, Muniz Jr. debruça-se sobre o sétimo capítulo de Art Worlds, intitulado "Editing", no qual o sociólogo define como momentos editoriais todos aqueles que, durante a criação, envolvem tomadas de decisões com base no agenciamento tanto do conhecimento prévio que se tem do mundo artístico, quanto das referidas projeções acerca da recepção da obra. Por fim, Muniz Jr. contrapõe o conceito de mundo, de acordo com Becker, ao de campo, segundo Pierre Bourdieu. Apesar dessas noções se aproximarem no sentido em que "designam espaços sociais de produção simbólica" (p. 85), ambas comportam diferenças fundamentais: "se na obra de Becker a análise dos mundos artísticos recai sobre as interações sociais, com ênfase nos modos de cooperação e trabalho conjunto, nas pesquisas de Bourdieu o objeto central são as relações sociais, com ênfase nas disputas pelo acúmulo de capitais" (p. 88). Feita essa advertência, Muniz Jr., ao retomar as considerações que abrem o capítulo, encerra-o com uma interessante hipótese: “não seria possível dizer que a 'teoria dos mundos' de Becker é mais adequada para investigar o microuniverso do editing, ao passo que a 'teoria dos campos' de Bourdieu cai como uma luva ao estudo do macrouniverso do publishing?" (p. 89) Aqui novamente, ao propor a convergência de diferentes perspectivas teóricas sem deixar de levar esclarecidamente em conta tanto as 
potencialidades quanto limitações inerentes a cada uma delas, Muniz Jr. é bem sucedido em sua proposta de abertura para uma maior pluralidade epistemológica.

No quinto e último capítulo, "São editores': um retrato de grupo", MunizJr. reflete sobre o imaginário e as representações que procuram apreender a atividade editorial e seus agentes. Para tanto, o pesquisador analisa $A$ versão do autor (2004), livro organizado por Jonathan Busato, Laura Moreira e Milton Nakanishi e publicado pela Com-Arte. A obra reúne textos de vinte escritores literários convidados a exporem seus pontos de vista sobre a relação entre autor e editor. Inicialmente, Muniz Jr. contextualiza os textos que compõem o volume a partir de variáveis como, por exemplo, a faixa etária dos colaboradores, atividade profissional que exercem paralelamente à literatura, o gênero literário pelo qual ficaram célebres, os estados brasileiros em que nasceram e o gênero literário da colaboração enviada. Descrito o panorama diversificado de colaboradores, Muniz Jr. analisa caso por caso, pinçando exemplos de como "essa multiplicidade de perspectivas produz imagens da relação autor-editor que vão da harmonia ao conflito" (p. 98). Na subseção final do capítulo, o pesquisador empreende análise detalhada da colaboração enviada por Fernando Bonassi, o poema "São editores", texto intensamente polifônico no qual as diferentes vozes se impõem sobretudo por justaposição e acúmulo, aparentando uma relação mais arbitrária do que necessariamente lógica. Porém, trata-se "de um vozerio não totalmente arbitrário, porque [...] o ritmo impresso ao poema impõe uma organização mínima do campo esboçado, na forma de afinidades e oposições que orientam o olhar para determinadas relações de força e sentido" (p. 117). Assim, para Muniz Jr., o poema "São editores" exerce função estratégica em $A$ versão do autor, já que nesse texto "Bonassi amarra polifonicamente as outras vozes do livro, plasmadas finalmente na contradição entre os caracteres sagrado e mundano da atividade editorial" (p. 121). De forma homóloga, se a abordagem de Muniz Jr. neste capítulo - cuja subseção final converte-se em verdadeiro estudo literário - é levemente destoante em relação à dos capítulos anteriores, ela está não obstante inscrita com êxito no propósito maior do autor de, em respeito à própria natureza pluridisciplinar do mundo editorial, realizar 
um levantamento de possíveis afinidades epistemológicas para, em seguida, ensaiar a resolução de teses por vezes conflitantes.

Diante de tantas publicações voltadas a profissionais das áreas de edição, preparação e revisão textual caracterizadas por viés predominantemente normalizador e prescritivo, pode-se afirmar que Tinha um editor no meio do caminho se configura como obra oportuna e bem-vinda para o estímulo - raro porém vital - da reflexão por parte desses profissionais acerca da atividade que exercem. Para isso, além da clareza argumentativa e da fiabilidade metodológica de Muniz Jr., apontadas ao longo desta apresentação, são especialmente profícuas as subseções "Vamos pensar em edição" que, posicionadas no fim de cada capítulo, fornecem pistas para o prosseguimento da discussão em pauta na forma de indicações bibliográficas complementares e de novas questões a serem (re)colocadas em perspectiva. José de Souza MunizJr., sem perder de vista em sua análise a incessante mão dupla entre produtos e processos editoriais, dedica igual atenção tanto aos seus aspectos mais intelectualmente densos como àqueles tomados por simples ou naturais - e que por isso mesmo arriscam desviar nossa atenção da verdadeira complexidade subjacente às aparências -, fazendo com que a leitura de seu livro seja desafiadoramente proveitosa tanto para profissionais experientes quanto para iniciantes, independentemente do estágio do caminho em que se encontram.

\section{REFERÊNCIA}

MUNIZ JÚNIOR, José de Souza. Tinha um editor no meio do caminho: questões

contemporâneas de edição, preparação e revisão textual. Divinópolis: Artigo A, 2018.

\section{Mário Vinícius Ribeiro Gonçalves}

Mestre em Design Gráfico Multimídia, editor, tipógrafo e designer gráfico mariovinicius20@gmail.com 